\title{
Psychologist Versus Client Perspectives in the Assessment of Psychopathology
}

\author{
Brian Bolton \\ Arkansas Rehabilitation Research and \\ Training Center, University of Arkansas
}

\begin{abstract}
The Minnesota Multiphasic Personality Inventory (MMPI) and the Psychiatric Status Schedule (PSS) were administered to two samples of clients who were participating in large-scale investigations of the rehabilitation counseling process $(N=108)$ and private psychotherapy $(N=113)$. The MMPI summarized the clients' subjective views of their emotional status while the PSS provided an assessment that had been filtered through the psychologists' perspectives. Statistical analyses of the resulting multivariable-multimethod matrix revealed a substantial convergence of client and psychologist perspectives. The assessment of depression was the symptom area in which the greatest agreement occurred ( $r$ 's of .60 and .70); canonical correlations which used all MMPI and PSS scales approached the theoretical maximum values ( $R_{c}$ 's of .75 and .84). Further analyses suggested that the PSS provides a broader assessment of psychopathology than does the MMPI by summarizing unique diagnostic information. While an average of $40 \%$ of the variance in the MMPI sets was predictable from the PSS, only $16 \%$ of the PSS variance was predictable from the MMPI.
\end{abstract}

Clinical and counseling practitioners have long recognized that clients' views of their mental and emotional status are often inconsistent with professional opinion. This apparent lack of congruence between the "objective" assessment and the "subjective" perspective of the client

APPLIED PSYCHOLOGICAL MEASUREMENT

Vol. 1, No. 4 Fall 1977 pp. 533-542

(c) Copyright 1977 West Publishing Co. has not been adequately documented by research, even though the issue has major implications for diagnostic and treatment programs. Some fundamental questions are: What are the criteria of emotional disturbance? Does perceived distress outweigh behavioral symptomatology in the assessment of maladjustment? Whose perspective do we value more? The present study was designed to evaluate the congruence (or lack thereof) of professional and client perspectives in the assessment of psychopathology.

In a now classic paper, Campbell and Fiske (1959) outlined a research paradigm for assessing the convergent and discriminant validity of psychological measures, introduced the notion of a trait-method unit which suggests that psychological construct and measurement method may be inseparable, and documented the pervasiveness of method variance in psychological measurement.

While most research psychologists have accepted the validity of the Campbell-Fiske analysis and conclusions, which have been supported by subsequent research, at least one prominent psychometric personologist has resisted the conclusion that method variance extensively confounds trait measurement. ${ }^{1}$ Cattell (1973) has refined his perturbation theory over a period of

'Two recent book reviews suggest that there may be a broader-based minority opinion which devalues the Camp- 
several decades. The principle of "indifference of the medium" and the concept of "instrumentfree trait patterns" postulate that, while traits cannot be measured without some contamination by the method of observation, a source trait does exist which can be isolated by using the convergence of several methods of measurement.

In direct contrast to Cattell, Fiske (1971) has emphasized "the fact that observations from different perspectives are so different in quality and so independent empirically that they should be treated as relevant to separate constructs or subconstructs" (p. 59). Fiske defined perspective as a viewpoint from which personality phenomena can be observed (subject, peer, psychologist, etc.) and noted that research findings indicate that the more dissimilar the viewpoints from which observations are made, the lower the relationship between them. In summary, Fiske's position maintains that personality traits are "perspective-specific."

The Campbell-Fiske multitrait-multimethod paradigm requires two or more methods (or perspectives), ${ }^{2}$ each measuring two or more of the same traits. If the traits measured by the different methods (or from different perspectives) are not identical but represent the same personality domain, then the design constitutes a multivariable-multimethod assessment. The validity diagonal entries are the most important elements in the multitrait-multimethod analysis because they indicate the extent of convergence across methods. In the multivariable-multimethod design, the relatively straight-forward interpretation of the validity diagonal may be replaced by more comprehensive analysis of the heteromethod matrix. In addition to inspection of the heteromethod correlations for indications of logical convergences, several multivariate procedures have been suggested to assess the convergence or communality at the dimensional level. Principal components analysis (unrotated), canonical correlation analysis, and factor analysis are potentially applicable procedures.

\section{Empirical Studies of Inter-perspective Convergence}

Nine studies were located in the literature which directly addressed the issue of convergence of perspectives in the domain of psychopathology. Ellsworth, Foster, Childers, Arthur, and Kroeker (1968) conducted a large-scale investigation of the behavioral adjustment of 178 male schizophrenics. They found modest correlations (few were above .30) between patients' self-reported psychopathological symptoms on a 17-item scale and a variety of behavioral ratings completed at several points in time by hospital staff and the patients' relatives. Park, Uhlenhuth, Lipman, Rickels, and Fisher (1965) compared ratings of distress level and improvement during drug treatment by 138 neurotic patients and their psychiatrists. The median correlation for a 64-item modification of the Hopkins Symptom Checklist Discomfort Scale was .51.

Four relevant studies used the Hamilton Rating Scale for Depression. Prusoff, Klerman, and Paykel (1972) found correlations of .36 and .81 during the acute episode and at recovery, respectively, between total severity scores derived from the Hamilton and a self-report inventory completed by 147 depressed patients. Carroll, Fielding, and Blashki (1973) reported a correlation of .41 between the Hamilton and the Zung Self-Rating Depression Scale for 67 depressed patients. Schwab, Bialow, and Holzer (1967) reported a correlation of .75 between the

bell-Fiske position. McClelland (1975) chides Korman (and the majority of psychologists) by stating that "It never occurs to him that Campbell and Fiske could be wrong-nor would it occur probably to most readers of this review-but even a quick look at their argument reveals that it is mischievously democratic (p. 877)." In his generally critical review of Wylie's (1974) revised edition of The Self-Concept. Fisher (1975) seems to be raising the same issue as McClelland. He faults Wylie for her excessive emphasis on convergent and discriminant validity evidence in evaluating self-concept measures, while not giving sufficient weight to predictive validity and theoretical considerations.

${ }^{2}$ For the purposes of this paper, the terms method and perspective can be used interchangeably; however, it will be clear that the measurement methods and the two perspectives are confounded. 
Hamilton and the Beck Depression Inventory for 153 medical patients while Williams, Barlow, and Agras (1972) found that the same instruments correlated .82 for a sample of ten depressed psychotic patients.

Three pertinent MMPI studies have been published. May and Tuma (1964) found low correlations (a range from .13 to .37) between three MMPI scales $(P a, P t$, and $S c)$ and various psychiatric rating scales completed by nurses, physicians, and psychiatrists for 100 schizophrenic patients. Spitzer, Fleiss, Endicott, and Cohen (1967) reported correlations between a priori-selected MMPI scales and the 13 symptom scales of the Mental Status Schedule (the precursor of the Psychiatric Status Schedule) for 60 female schizophrenics: the coefficients ranged from .08 to .70. Lorr and Gilberstadt (1972) compared two diagnostic typologies, one based on the Inpatient Multidimensional Psychiatric Scale and the other on MMPI profiles, for 335 hospitalized psychotics. The degree of overlap between the self-report and interview-based typologies was slight.

All of these investigations were carried out in psychiatric settings using hospitalized patients as subjects. A variety of instruments of the selfreport and rating scale format were employed and correlations ranged from nonsignificant to high, with the higher correlations found when the samples were heterogeneous in composition, the variation in behavioral symptomatology was extensive, and the item content and format of the measuring instruments employed were similar.

The present study goes beyond the narrow limits of the previously conducted investigations in several respects, i.e., the subjects were from non-hospitalized populations, the availability of two independent samples using the same instruments provided an immediate replication of results, and the multivariate nature of the statistical analysis increased the precision of the conclusions.

\section{Method}

\section{Subjects}

Two samples of clients who participated in separately conducted, nationwide studies served as subjects for the present investigation. In conjunction with a study of the rehabilitation counseling process (Bozarth, Rubin, Krauft, Richardson, \& Bolton, 1974), 108 applicants for services with emotional disabilities completed the Mini-Mult (in written form) and were interviewed by private psychologists who completed the Psychiatric Status Schedule (PSS). The rehabilitation sample had the following characteristics: $56 \%$ male; $90 \%$ white; $22 \%$ less than 20 years of age and $23 \%$ over 40 years; $19 \%$ married; and psychiatric diagnoses as follows: $16 \%$ neurotic, $16 \%$ psychotic, $42 \%$ behavioral disorders, and $26 \%$ alcoholic.

A sample of 113 clients completed the MMPI and were administered the PSS as pretest measures in conjunction with a study of the effectiveness of psychotherapists in private practice (Mitchell, Truax, Bozarth, \& Krauft, 1973). The sample is characterized as follows: $41 \%$ male; $99 \%$ white; $8 \%$ less than 20 years of age and $12 \%$ over 40 years; $35 \%$ married; and psychiatric diagnoses as follows: $28 \%$ neurotic, $37 \%$ schizophrenic, $19 \%$ behavioral disorders, and $16 \%$ with no emotional disorder.

Table 1 presents descriptive statistics for both samples on the MMPI (or Mini-Mult) and the PSS. The large differences between the MMPI and the PSS $T$-score profiles reflect the differences in the respective norm groups, i.e., hospital visitors for the MMPI and psychiatric inpatients for the PSS. The MMPI profiles for the rehabilitation and psychotherapy samples were similar; however, several of the PSS Subjective Distress symptom scales suggest differences between the samples.

\section{Instruments}

As indicated above, clients' views of their psychological status were quantified via the MMPI (or Mini-Mult) while psychologists' viewpoints 
Table 1

Means and Standard Deviations on the MMPI and PSS for Two Research Samples ${ }^{a}$

\begin{tabular}{|c|c|c|c|c|}
\hline \multirow[b]{2}{*}{ MMPI or Mini-Mult ${ }^{b}$} & \multicolumn{2}{|c|}{$\begin{array}{l}\text { Rehabilitation } \\
\text { Sample }(N=108)\end{array}$} & \multicolumn{2}{|c|}{$\begin{array}{l}\text { Psychotherapy } \\
\text { Sample }(\mathrm{N}=113)\end{array}$} \\
\hline & $M$ & SD & $\mathrm{M}$ & SD \\
\hline $\begin{array}{l}\text { Validity Scales } \\
\text { I scale } \\
\text { F scale } \\
\text { K scale }\end{array}$ & $\begin{array}{l}51.3 \\
61.9 \\
50.4\end{array}$ & $\begin{array}{r}7.9 \\
11.8 \\
8.0\end{array}$ & $\begin{array}{l}46.8 \\
64.6 \\
50.1\end{array}$ & $\begin{array}{r}6.8 \\
11.1 \\
9.6\end{array}$ \\
\hline $\begin{array}{l}\text { Clinical Scales } \\
\text { Hypochondriasis (Hs) } \\
\text { Depression (D) } \\
\text { Hysteria (Hy) } \\
\text { Psychopathic Deviate (Pd) } \\
\text { Paranoia (Pa) } \\
\text { Psychasthenia (Pt) } \\
\text { Schizophrenia (Sc) } \\
\text { Hypomania (Ma) }\end{array}$ & $\begin{array}{l}60.0 \\
70.1 \\
64.7 \\
74.6 \\
64.9 \\
66.3 \\
70.5 \\
59.4\end{array}$ & $\begin{array}{r}13.4 \\
14.4 \\
10.9 \\
13.1 \\
14.1 \\
15.2 \\
16.8 \\
9.2\end{array}$ & $\begin{array}{l}58.9 \\
72.3 \\
63.7 \\
71.0 \\
64.5 \\
72.7 \\
73.8 \\
61.0\end{array}$ & $\begin{array}{l}12.0 \\
13.9 \\
10.1 \\
12.6 \\
12.6 \\
13.7 \\
14.4 \\
12.4\end{array}$ \\
\hline PSS & & & & \\
\hline $\begin{array}{l}\text { I. Subjective Distress: } \\
\text { 1. Depression-Anxiety } \\
\text { 2. Daily Routine } \\
\text { 3. Social Isolation } \\
\text { 4. Suicide } \\
\text { 5. Somatic concern }\end{array}$ & $\begin{array}{l}43.6 \\
43.8 \\
45.3 \\
46.5 \\
46.4\end{array}$ & $\begin{array}{r}10.4 \\
6.8 \\
9.5 \\
9.0 \\
6.8\end{array}$ & $\begin{array}{l}52.3 \\
47.6 \\
49.1 \\
48.8 \\
49.8\end{array}$ & $\begin{array}{r}10.3 \\
9 \cdot 4 \\
10.3 \\
9.4 \\
10 \cdot 4\end{array}$ \\
\hline $\begin{array}{l}\text { II. Behavioral Disturbance: } \\
\text { 6. Speech Disorganization } \\
\text { 7. Inappropriate Affect } \\
\text { 8. Agitation-Excitement } \\
\text { 9. Interview Belligerence } \\
\text { 10. Disorientation } \\
\text { 11. Retardation }\end{array}$ & $\begin{array}{l}47.3 \\
47.3 \\
47.8 \\
46.5 \\
47.1 \\
47.7\end{array}$ & $\begin{array}{l}7.4 \\
7.0 \\
6.9 \\
1.5 \\
3.5 \\
7.7\end{array}$ & $\begin{array}{l}46.8 \\
47.6 \\
49.1 \\
47.4 \\
46.5 \\
49.4\end{array}$ & $\begin{array}{r}5.4 \\
5.7 \\
10.0 \\
6.0 \\
2.4 \\
9.7\end{array}$ \\
\hline $\begin{array}{l}\text { III. Impulse Control Disturbance: } \\
\text { 12. Antisocial Impulses } \\
\text { 13. Drug Abuse } \\
\text { 14. Reported Overt Anger }\end{array}$ & $\begin{array}{l}49.3 \\
49.7 \\
48.6\end{array}$ & $\begin{array}{l}9.1 \\
7.5 \\
7.3\end{array}$ & $\begin{array}{l}50.4 \\
51.0 \\
51.0\end{array}$ & $\begin{array}{r}9.4 \\
13.5 \\
9.9\end{array}$ \\
\hline $\begin{array}{l}\text { IV. Reality Testing Disturbance: } \\
\text { 15. Grandiosity } \\
\text { 16. Suspicion-Persecution }\end{array}$ & $\begin{array}{l}48.0 \\
47.0\end{array}$ & $\begin{array}{l}5.1 \\
7.4\end{array}$ & $\begin{array}{l}48.6 \\
47.2\end{array}$ & $\begin{array}{l}8.4 \\
6.8\end{array}$ \\
\hline $\begin{array}{l}\text { V. (Singlet) } \\
\text { 17. Alcohol Abuse }\end{array}$ & 53.8 & 15.3 & 48.7 & 8.8 \\
\hline
\end{tabular}

all scores are T-scores.

bThe following scales were K-corrected: Hs, Pd, Pt, Sc, and Ma. 
were summarized using the Psychiatric Status Schedule (PSS). In Fiske's (1971) scheme of modes of personality measurement, the MMPI is categorized within the self-description mode and the PSS falls in the observation of behavior mode. However, Fiske (p. 78) points out that with some structured interview procedures such as the PSS, the observation of behavior and selfdescription modes differ only on the basis of who (client or psychologist) records the response. Most clinicians would disagree with Fiske and argue that the situation in which the response is made (private vs. public) may have substantial influence on the accuracy or truthfulness of the response.

Available evidence indicates that the MMPI is the most popular extant personality inventory for research purposes (Buros, 1975). An abbreviated version known as the Mini-Mult (Kincannon, 1968) has also proved to be rather popular, although the accumulated evidence suggests that it may not be an adequate substitute for the full-length MMPI when the application uses standard profile interpretation procedures (Hoffmann \& Butcher, 1975). However, when the application treats the scale scores as dimensions, as the current study does, the substitution is warranted. The average correlation between the corresponding Mini-Mult and MMPI scales is .85 (Hoffmann \& Butcher, 1975, p. 34). The eight clinical scales which are measured by both the MMPI and the Mini-Mult are listed in Table 1 ( $M f$ and $S i$ are not included in the MiniMult). ${ }^{3}$

The second edition of the PSS evolved from a research program carried out over a decade by Spitzer, Endicott, Fleiss, and Cohen (1970). The PSS is a standardized interview which consists of 321 precoded items which focus on the subject's symptoms and functioning during the past week. The majority of the items (225) are scored on 17 symptom scales which were derived through a series of factor analytic studies. The 17 symptom scales may be reduced to four summary scales which represent second-order factors. The symptom scales are listed under their respective summary scales in Table 1 . It should be noted that the median interjudge reliability coefficient for the 17 symptom scales was estimated to be .89 (Spitzer, et al., 1970, p. 48 ).

\section{Procedures}

The most direct approach to assessing the extent of convergence across perspectives is the examination and summary of the heteromethod matrix of correlations. For multivariable-multimethod designs, however, it is desirable to go beyond the level of zero-order correlations. The appropriate technique for evaluating the degree of relationship at the dimensional level is canonical correlation analysis. Weights for the first pair of canonical variates are determined so that the composite scores from the two data sets (perspectives) are maximally correlated. Thus, the first canonical correlation indicates the maximum degree of convergence across perspectives.

While the first canonical correlation squared represents the variance overlap of the first pair of canonical variates, it does not indicate the amount of variance common to the two sets of variables. Weiss (1972) outlined a procedure, redundancy analysis, that provides a framework for interpreting the canonical variates in terms of the total variance subsumed in the variable sets. Redundancy analysis, then, summarizes the predictability of each set of variables from the other set.

To further clarify the pattern of correlations in the heteromethod matrices, the monomethod matrices for each variable set (MMPI and PSS) were condensed via unrotated principal components analysis for each sample separately. The magnitude of the successive components provides direct evidence regarding the behavioral complexity of the two instruments.

\footnotetext{
${ }^{3}$ The 566-item version of the MMPI was completed by the psychotherapy subjects and the 71-item Mini-Mult was employed in the rehabilitation counseling investigation.
} 


\section{Results}

\section{Bivariate Correlations}

Table 2 contains the heteromethod correlations among the eight MMPI clinical scales and the 17 symptom scales of the PSS for each of the research samples. The pattern of relationships is easily discernible. Several of the PSS Subjective Distress symptom scales are substantially correlated with several MMPI clinical scales. In particular, Depression-Anxiety, Daily Routine, and Suicide correlated with Depression, Psychasthenia, and Schizophrenia. A number of relationships of lesser magnitude are noteworthy, e.g., Somatic Concern and Hypochondriasis, Suspicion-Persecution and Paranoia, etc. The strongest support for convergence across perspectives is clearly provided by the correlations between PSS Depression-Anxiety and MMPI Depression and Psychasthenia. These correlations approached the theoretical maximum when unreliability of the scales is taken into consideration.

The pattern of heteromethod correlations is remarkably similar for the two samples. The only possible difference concerns a PSS symptom scale, Reported Overt Anger. In general, the correlations for the rehabilitation sample were slightly lower; this attenuation may be reasonably attributed to the restricted variability of the rehabilitation sample on many of the PSS scales and the lower reliability of the Mini-Mult scales.

\section{Canonical Analysis}

The first canonical correlations were $.75\left[\chi^{2}\right.$ $(136)=196.17, p<.001]$ and $.84\left[\chi^{2}(136)=\right.$ $278.80, p<.001]$ for the rehabilitation and psychotherapy samples, respectively. These values indicate that, within the limits of unreliability, psychologist and client perspectives converge to the same global assessment of extent of psychopathology. it is clear from the heteromethod correlation matrices, however, that the basis of the psychologists' global evaluation is contained in only a few of the PSS symptom scales.
The results of the redundancy analyses, which are summarized in Tables 3 and $\mathbf{4}$, formalize the asymmetric relationship between the MMPI and the PSS. Specifically, 37\% (rehabilitation sample) and $43 \%$ (psychotherapy sample) of the total MMPI variance is predictable from the PSS set, while only $14 \%$ (rehabilitation sample) and $18 \%$ (psychotherapy sample) of the total PSS variance is predictable from the MMPI. Furthermore, it is apparent that DepressionAnxiety (PSS) and Depression, Psychasthenia, and Schizophrenia (MMPI) are the largest contributors to the variance common to the two perspectives.

\section{Principal Components Analysis}

The variance distributions of the successive principal components extracted from the MMPI and PSS monomethod matrices provide further clarification of the patterns of correlations and variance distributions in the heteromethod matrices and the redundancy statistics. The first three components of the MMPI accounted for $66.1 \%, 10.2 \%$, and $8.9 \%$ (rehabilitation sample) and $53.9 \%, 17.2 \%$, and $9.9 \%$ (psychotherapy sample) of the total variance in the eight clinical scales. In contrast, the first five components of the PSS accounted for $26.1 \%, 15.2 \%, 8.5 \%$, $7.4 \%$, and $6.6 \%$ (rehabilitation sample) and $20.2 \%, 16.6 \%, 10.2 \%, 8.3 \%$, and $6.9 \%$ (psychotherapy sample) of the total variance in the 17 symptom scales. These distributions indicate that the MMPI (and Mini-Mult) tap a central core of self-reported emotional maladjustment whereas the PSS provides a broader assessment of individual differences in psychopathological symptoms. ${ }^{4}$ This result is consistent with the finding (see Table 2) that any PSS scale which correlates wiih one MMPI scale also correlates with several others.

\footnotetext{
${ }^{4}$ The comparison may be somewhat misleading due to the multiply-scored items in the MMPI; thus, the magnitude of the first principal component is, in part, an artifact of the scoring procedure which forces+correlations among the scales.
} 


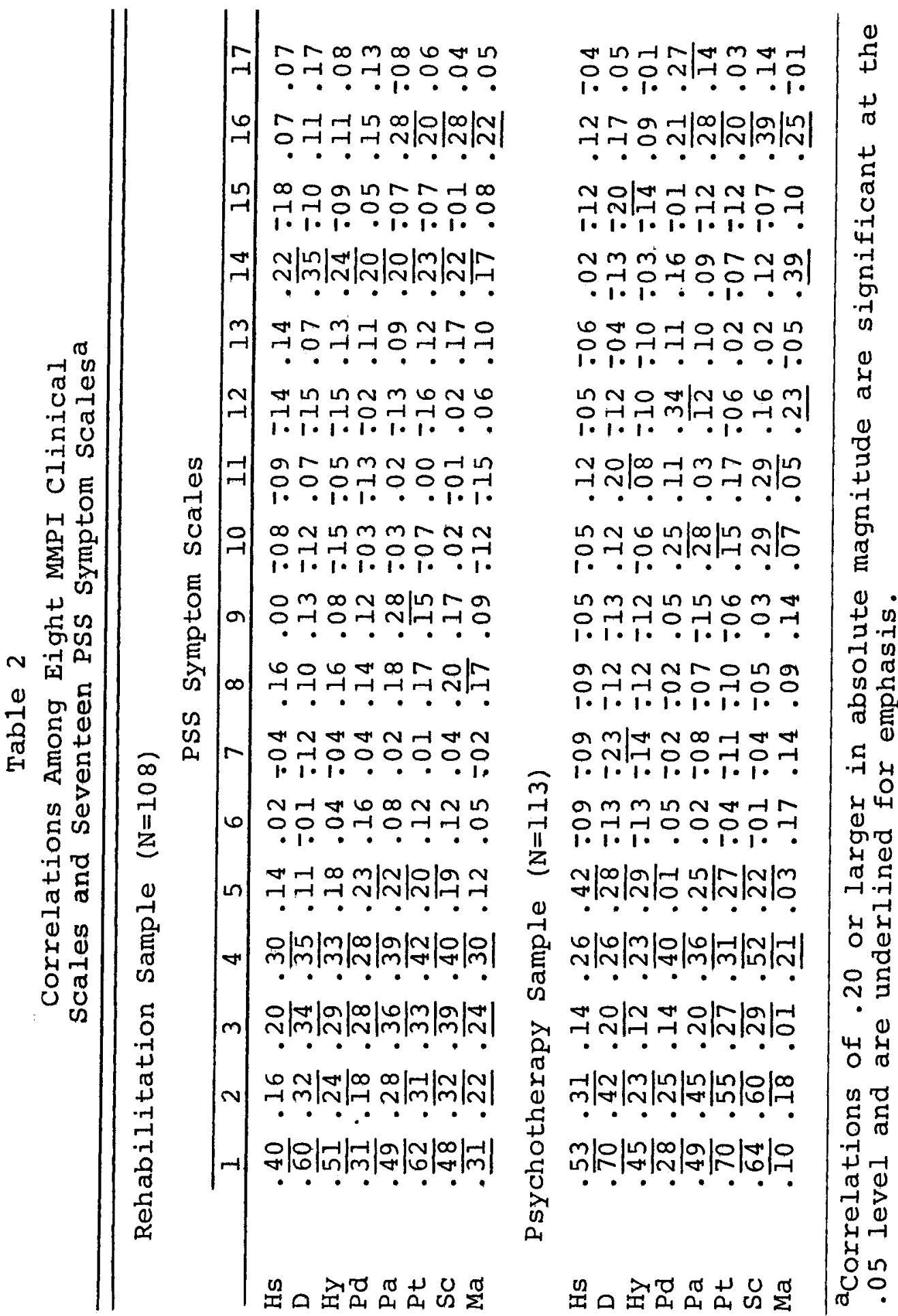




\begin{tabular}{|c|c|c|c|c|c|}
\hline \multirow[b]{2}{*}{ MMPI } & \multicolumn{2}{|c|}{ Rehabilitation Sample } & \multicolumn{3}{|c|}{ Psychotherapy Sample } \\
\hline & $\mathrm{CVI}$ & Totala & CVI & $\mathrm{CV} 2^{\mathrm{C}}$ & Total \\
\hline $\begin{array}{l}\mathrm{Hs} \\
\mathrm{D} \\
\mathrm{Hy} \\
\mathrm{Pd} \\
\mathrm{Pa} \\
\mathrm{Pt} \\
\mathrm{Sc} \\
\mathrm{Ma} \\
\end{array}$ & $\begin{array}{r}.30 \\
.43 \\
.39 \\
.12 \\
.29 \\
.47 \\
.26 \\
.14 \\
\end{array}$ & $\begin{array}{r}.36 \\
.48 \\
.42 \\
.24 \\
.36 \\
.48 \\
.36 \\
.24 \\
\end{array}$ & $\begin{array}{l}.27 \\
.59 \\
.23 \\
.08 \\
.29 \\
.55 \\
.49 \\
.00 \\
\end{array}$ & $\begin{array}{l}.01 \\
.02 \\
.02 \\
.14 \\
.02 \\
.00 \\
.08 \\
.11 \\
\end{array}$ & $\begin{array}{r}.39 \\
.63 \\
.30 \\
.28 \\
.44 \\
.58 \\
.59 \\
.25 \\
\end{array}$ \\
\hline $\mathrm{Rd}^{\mathrm{b}}$ & .30 & .37 & .31 & .05 & .43 \\
\hline
\end{tabular}

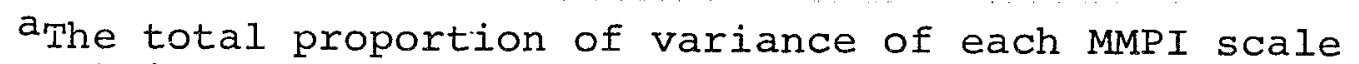
explainable by the entire set of PSS variables is the SMC.

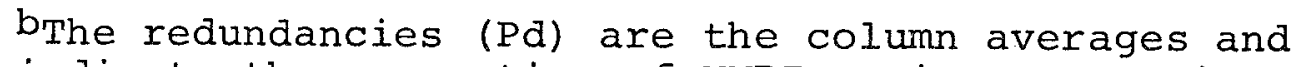
indicate the proportion of MMPI variance associated with successive canonical variates and the total set.

CThe second canonical correlation of .64 ( $p<.005)$ for the psychotherapy sample was the only one to reach statistical significance.

Several points regarding the measurement procedures may have detracted from the validity of the comparison of client and psychologist perspectives in this study; e.g., (1) the two instruments were constructed following different methodologies (empirical versus factor analytic); (2) standard MMPI diagnostic schemes utilize the individual profile rather than treating the scales as dimensional constructs; (3) some critics (e.g., Edwards, 1970) contend that the MMPI scales measure social desirability and acquiescent responding rather than psychological traits; and (4) the PSS symptom scale distributions are positively skewed because the instrument was developed primarily for use in psychiatric settings. In general, these measurement problems serve to make the obtained results all the more impressive, since their existence could only have attenuated the heteromethod correlations.

\section{Summary}

The major findings of this study can be summarized as follows:

1) The standard clinical scales of the MMPI assess a global dimension of self-perceived emotional difficulty, as evidenced by the magnitude of the first principal component and the consistent pattern of correlations with the PSS scales. In contrast, the PSS provides a multidimensional assessment of psychopathology from a relatively objective point of view. 


\section{Table 4}

Proportions of PSS Variance Associated with the Significant Canonical Variates (CVs)

\begin{tabular}{|c|c|c|c|c|c|}
\hline \multirow[b]{2}{*}{ PSS } & \multicolumn{2}{|c|}{ Rehabilitation sample } & \multicolumn{3}{|c|}{ Psychotherapy } \\
\hline & CVI & Totala & CV1 & $\mathrm{CV} 2$ & Total \\
\hline 1 & .42 & .45 & .56 & .00 & .58 \\
\hline 2 & .10 & .16 & .32 & .04 & .40 \\
\hline 3 & .11 & .19 & .08 & .01 & .11 \\
\hline 4 & .18 & .22 & .16 & .14 & .32 \\
\hline 5 & .03 & .09 & .08 & .03 & .22 \\
\hline 6 & .00 & .08 & .01 & .02 & .06 \\
\hline 7 & .00 & .06 & .03 & .02 & .08 \\
\hline 8 & .03 & .07 & .02 & .01 & .03 \\
\hline 9 & .02 & .11 & .01 & .03 & .10 \\
\hline 10 & .02 & .08 & .05 & .11 & .21 \\
\hline 11 & .00 & .13 & .06 & .03 & .14 \\
\hline 12 & .04 & .13 & .00 & .19 & .22 \\
\hline 13 & .01 & .05 & .00 & .01 & .07 \\
\hline 14 & .07 & .14 & .01 & .09 & .18 \\
\hline 15 & .01 & .08 & .03 & .01 & .06 \\
\hline 16 & .07 & .14 & .08 & .10 & .20 . \\
\hline 17 & .00 & .13 & .01 & .06 & .13 \\
\hline$R a^{b}$ & .06 & .14 & .09 & .05 & .18 \\
\hline
\end{tabular}

asame as Table 3 with MMPI and PSS interchanged. bSame as Table 3 with PSS substituted for MMPI.

2) The various statistical analyses of the MMPI and PSS scales suggest that the PSS Subjective Distress scales (Depression-Anxiety in particular) tap the domain of self-reported disturbance assessed by the MMPI. The other major areas of the PSS assess aspects of impaired functioning which are not covered by the MMPI. Thus, the PSS provides a broader assessment of psychopathology than the MMPI by collecting diagnostic information which goes beyond the MMPI data range.

3) The implication of these findings for clinical and counseling practice is that the MMPI (or any of its short forms) should not be used alone in diagnosing the nature and extent of emotional disturbance; some form of structured interview should be employed to provide an additional perspective on the client's self-perceived distress, as well as ascertaining unique information regarding the degree of impairment in other areas of functioning.

\section{References}

Bozarth, J. D., Rubin, S. E., Krauft, C. C., Richardson, B. K., \& Bolton, B. Client counselor interaction, patterns of service, and client outcome: Overview of project-conclusions and implications. Fayetteville: Arkansas Rehabilitation Research and Training Center, 1974. 
Buros, O. K. (Ed.) Personality tests and reviews $I I$. Highland Park, NJ: The Gryphon Press, 1975.

Campbell, D. T., \& Fiske, D. W. Convergent and discriminant validation by the multitrait-multimethod matrix. Psychological Bulletin, 1959, 56. 81-105.

Carroll, B. J., Fielding, J. M., \& Blashki, T. G. Depression rating scales. Archives of General Psychiatry, 1973, 28, 361-366.

Cattell, R. B. Personality and mood by questionnaire. San Francisco: Jossey-Bass, 1973.

Edwards, A. L. The measurement of personality traits by scales and inventories. New York: Holt, 1970.

Ellsworth, R. B., Foster, L., Childers, B., Arthur, G., \& Kroeker, D. Hospital and community adjustment as perceived by psychiatric patients, their families, and staff. Journal of Consulting and Clinical Psychology Monograph Supplement, 1968,32 (5, Pt. 2), 1-41.

Fisher, S. Review of Wylie, R. C. The self-concept, (Vol. I). (Rev. ed.). Contemporary Psychology, 1975, 20, 729-730.

Fiske, D. W. Measuring the concepts of personality. Chicago: Aldine, 1971.

Hoffmann, N. G., \& Butcher, J. N. Clinical limitations of three Minnesota Multiphasic Personality Inventory short forms. Journal of Consulting and Clinical Psychology, 1975, 43, 32-39.

Kincannon, J. Prediction of the standard MMPI scale scores from 71 items: The Mini-Mult. Journal of Consulting and Clinical Psychology, 1968, 32, 319-325.

Lorr, M., \& Gilberstadt, H. A comparison of two typologies for psychotics. The Journal of Nervous and Mental Disease, 1972, 155, 144-148.

May, P. R., \& Tuma, A. H. Choice of criteria for the assessment of treatment outcomes. Journal of Psychiatric Research, 1964, 2, 199-209.

McClelland, D. Review of Korman, A. L. The psychology of motivation. Contemporary Psychology, 1975, 20, 876-878.

Mitchell, K. M., Truax, C. B., Bozarth, J. D., \& Krauft, C. C. Antecedents to psychotherapeutic outcome. Fayetteville: Arkansas Rehabilitation Research and Training Center, 1973.
Park, L. C., Uhlenhuth, E. H., Lipman, R. S., Rickels, K., \& Fisher, S. A comparison of doctor and patient improvement ratings in a drug (meprobamate) trial. British Journal of Psychiatry, $1965,111,535-540$.

Prusoff, B. A., Klerman, G. L., \& Paykel, E. S. Concordance between clinical assessments and patients' self-report in depression. Archives of General Psychiatry, 1972, 26, 546-552.

Schwab, J. J., Bialow, M. R., \& Holzer, C. E. A comparison of two rating scales for depression. Journal of Clinical Psychology, 1967, 23, 94-96.

Spitzer, R. L., Endicott, J., Fleiss, J. L., \& Cohen, J. The Psychiatric Status Schedule: A technique for evaluating psychopathology and impairment in role functioning. Archives of General Psychiatry, 1970, 23, 41-55.

Spitzer, R. L., Fleiss, J. L., Endicott, J., \& Cohen, J. Mental Status Schedule: Properties of factor-analytically derived scales. Archives of General Psychiatry, 1967, 16, 479-493.

Weiss, D. J. Canonical correlation analysis in counseling psychology research. Journal of Counseling Psychology, 1972, 19, 241-252.

Williams, J. G., Barlow, D. G., \& Agras, W. S. Behavioral measurement of severe depression. Archives of General Psychiatry, 1972, 27, 330-333.

\section{Acknowledgments}

This research was supported by Grant No. 16-P. 56812/RT-13 from the Rehabilitation Services Administration, Office of Human Development, Department of Health, Education and Welfare. A preliminary version of the paper was presented on December 6, 1975, to the Arkansas Psychological Association meeting in Little Rock. The helpful suggestions provided by the Editor and an anonymous reviewer are gratefully acknowledged.

\section{Author's Address}

Brian Bolton, 346 N. West Avenue, Fayetteville, AR 72701. 